\title{
Non-Traditional Students in A Traditional College-A Feminist Perspective
}

\author{
Suaad M. Alshebou ${ }^{1}$ \\ ${ }^{1}$ Department of Educational Foundations and Administration, College of Basic Education, The Public Authority \\ for Applied Education and Training (PAAET), Ardhiya, Kuwait \\ Correspondence: Suaad M. Alshebou, Department of Educational Foundations and Administration, College of \\ Basic Education, The Public Authority for Applied Education and Training (PAAET), Ardhiya, Kuwait. Tel: \\ 965-9901-7118. E-mail: dralshebou@gmail.com
}

Received: March 2, 2019

doi:10.5539/ies.v12n7p28
Accepted: April 8, $2019 \quad$ Online Published: June 29, 2019

URL: https://doi.org/10.5539/ies.v12n7p28

\begin{abstract}
This research explores who participates in higher education (HE) in general and in the College of Basic Education (CBE) in particular from adult female learners' groups. This entails identifying the specific characteristics of these groups and understanding their learning experiences and obstacles they need to overcome. The study begins with an overview of the changing HE system in Kuwait followed by a review of relevant literature. This involves constructing a theoretical framework based upon attributes of adult education and setting out the critical feminist perspective at the heart of this study. The research follows both quantitative and qualitative methodologies. Research data was collected from female adult learners at CBE by using questionnaire and focus groups to elicit rich qualitative data as well as quantitative representative data. The study concludes with a discussion of policy and practice implications and areas for future research on adult learning and HE reforms in general. Outcomes of this research provide valuable lessons for policymakers as well as recommendations which seek to nourish an environment based on genuine equality of opportunity for all and inspiration for future generations of Kuwaiti women.
\end{abstract}

Keywords: adult learning, higher education, motivations, barriers, feminism, pre-service teacher education, women education

\section{Introduction}

The concept of lifelong learning, where people learn throughout their lives, has become forefront in the educational agendas which increases the importance of adult learning. In this sense, HE has become an important sector for providers, creating new opportunities for lifelong learning (Pires, 2009). Thus, local universities and colleges find themselves striving not only to improve their work, but also to make it responsive to such forces by setting new educational agendas and reshaping current policies and practices.

Generally, the decision of adults to return to education is driven by a variety of motivational orientations (Houle, 1961). Such orientations are affected by different factors: the policy and practice of HE institutions, labour market opportunities and individuals' personal and societal circumstances. This includes financial circumstances, attitudes to learning, educational background and qualifications, domestic situation, occupational status, career aspiration, and support from employers, friends and family members. Investigating the interaction of such factors can provide an understanding of adult learners' participation in HE in more details and greater depth. Also, knowledge relative to participation barriers can assist in attracting and retaining adult learners. As more adults will engage in HE, providers and instructors must be aware of barriers confronting adult learners and take a pro-active role to eliminate them.

Similar research in the Kuwaiti context is still unexplored. Literature reviewed indicated that research around adults' motives and barriers for participation in HE has been extensively examined in many different parts of the world although there is no evidence of similar studies in the Kuwaiti context. A few researches were conducted that explored adults' motivations in different educational settings such as illiteracy classes and continuing education departments (e.g. Alansari, 2002; Alshebou, 2010). As a faculty member working in a female college (CBE) (Note 1), this research was designed to focus intensively on female adult learners. The study explored who participates from female adult learners' groups in CBE. This entails identifying the specific characteristics 
of these groups and understanding their experiences in terms of their motives and obstacles they confront. Outcomes of this research can make a significant contribution to both research and implementation for policy strategies to increase adult participation in HE. It is also hoped that this research can enlighten HE professionals with practical ideas and plans to create a better campus environment and climate to better serve this growing population. To attain this, the study was guided by the following central questions:

1) What are the characteristics of female adult learners who participate in CBE in terms of their age, geographical regions, societal status, academic background and professional experience?

2) What are their motivations behind their participation in CBE?

3) How do they find their learning experience in terms of difficulties they face?

4) How do learners' perspectives vary according to their demographic and academic variables?

5) What suggestions can be made to improve both adult female learners' experiences and CBE efforts in increasing adult females' participation in HE and workforce?

\section{Higher Education in Kuwait}

The HE system in Kuwait comprises two public institutes and ten private universities and colleges. Added to this, the Ministry of HE has a scholarship programme that awards overseas scholarships for high school graduates. All HE institutions in Kuwait, except the Arab Open University, are traditionally geared towards provision for younger adults. A separate scheme of continuing education for employees in the public sector is also available. Under this scheme, study leave is granted with full salary to Kuwaitis who meet conditions stated by the Civil Service Authority.

Admission to HE institutes, excluding the private ones, is available free of charge to all Kuwaitis based on academic merit and some aptitude tests. However, entry to HE is highly competitive due to the limited places. Entry requirements are not flexible and they do not give any privileges to adults as admission is open to successful secondary school students who fulfil the conditions set by various faculties. Further to this, any suggestion of a quota for adult students is met with strong opposition as there are already insufficient places for school leavers who have met the standard entry requirements and who are being pushed to other education or work routes. Thus, access regulations and requirements for $\mathrm{HE}$ confirm the notion that $\mathrm{HE}$ is for the young.

Recently, CBE has widened its enrolment and started to accept non-traditional students. The National Center for Education Statistics (NCES) data clarifies seven characteristics to the term 'non-traditional'; these include: entry to college delayed, being a parent, employed, financially independent, attending part-time, and not having a high-school diploma. In Kuwait, non-traditional college students are mainly adult learners who wish to proceed their university or college studies at a later-than-typical age or those employees who wish to proceed their university studies.

The general expansion of HE and strategies to widen participation in CBE is evident in the rise of the number of adult entrants. According to the reports obtained from the Vice Dean for Admission and Registrarion, CBE accepted 327 non-traditional students, 134 males and 193 females (about 59\% female students) in the second semester of the academic year 2016-2017, whereas the total number of the adult learners' population in the first semester of the academic year of 2017-2018 was 1940 students (247 male students and 1693 female students) (CBE, 2018, p. 3).

Generally, HE institutions do offer some courses for adults, though the system is still more focused on traditional students than on adults. In Kuwait, there is no integral legal framework for adult education (Alshebou, 2007). It is widely acknowledged that the recognition, validation and accreditation (RVA) of non-formal and informal learning is a controversial issue in the Arab region (Singh, Idris, \& Chehab, 2018). While policy-makers have prioritized the issue on recognizing and validating non-formal learning, it remains a major challenge to develop systems that do this effectively. Providing high-quality guidance and assessments and implementing effective validation and recognition mechanisms of non-formal and informal adult learning are also top priorities in the country (Alshebou, 2010).

\section{Literature Review}

The study draws mainly upon literature relevant to motivations and barriers of adult learners, and attributes of adult education. As this study is concerned only with female adult learners, the feminist perspective is at the heart of this review. 


\subsection{The Feminist Perspective}

Given the idea that the sample of the research is only female adult learners, the question of feminism has come to the forefront. What is feminism? In her very short introduction to feminism, Margate Walters states that in the $20^{\text {th }}$ century, 'first wave' feminists had demanded civil and political equality, while in the 1970s, the 'second wave' feminism focused on sexual and family rights for women (Walters, 2005).

The problem of cross-cultural misunderstanding the term 'feminism' is a persistent one. There is an increasing recognition that, whereas 'western feminism' concentrates on gender discrimination, sexism and struggles against social and political inequalities. This notion is largely perceived as 'Eurocentric', and has nothing to say about local problems in different parts of the world like racial violence, health issues, deep-rooted local beliefs and practices, and ethnic biases (Walters, 2005).

In recent years, with the advent of new technology and internet, there has been a wider awareness among western feminists about demands of feminists from different parts of the world. Academic feminism has played an important role in this. It is widely acknowledged that the academic research has provided valuable insights into women's lives in other cultures, as well as differences and common causes.

Within the Arab region, many groups have struggled to define a specifically 'Islamic Feminism'; one that is built upon Islamic principles and local cultures and traditions (Walters, 2005). Researchers like Mazawi (2007), Kikoski (2008), Gallant (2010), and Kawanzaruwa (2015) attempted to examine what form of feminism best fits the Arab context. It became evident that there is a great emphasis on the importance of culture, family commitment, and the patriarchal system within which women enjoy security. Arab women are indeed fighting for an equal place in society but, crucially, they want to accomplish this without recourse to traditional feminist discourse (Kawanzaruwa, 2015). The first priority for women is to fulfill their domestic roles and duties and men maintain the legal and cultural authority to make decisions for women (Gallant, 2010). The expectations of women to be wives and mothers are still very strong: 'Women can't voluntarily admit to not wanting to become a wife or mother' (Gallant, 2010, p. 14). In some cases, societal expectations work to prevent full empowerment from being realized (Hafez, 2008; Alwoqayan, 2010).

In her study about the personal experiences of five Emirati women working in Dubai, Gallant (2010) argues that it is possible for Arab women to create a 'sustainable, emancipator movement by gradually challenging patriarchal discourses while still maintaining a connection to key societal norms' (Gallant, 2010, p. 14). It is important that women are not alienated from their society; hence there is a need to ensure that 'Arab feminism' considers Islamic principles and cultures as core to their emancipation.

As Gulf countries including Kuwait seek simultaneously to preserve their local traditions and culture while embracing modernity and innovation, challenges inevitably arise particularly when it comes to the education of women. Generally, in GCC countries, woman's education is seen as an approach of human investment to overcome the country's major economic challenges that hinder the development process, above all these challenges are the deficiency of human capital and the shortage of labour force. Increasing women participation in the workforce was emphasized in the GCC comprehensive development strategy agreed by the Supreme Council in its $18^{\text {th }}$ session in Abu Dhabi (Attiyah, 2010), as well as the most recent national development strategy 'Kuwait Vision 2035' (Supreme council for planning and development, 2007). It is believed that by raising female education and employment rates, Kuwait and other GCC countries can improve their gross domestic products (GDP) in the medium term (World Bank, 2016).

Nonetheless, the increasing numbers of women enrolling on HE courses have not been sufficient to free them from traditional hegemonic constrains. On the contrary, in Gulf countries, females still find themselves tied to long established cultural and traditional ideologies that play a strong role in impacting their education and employment preferences (Mazawi, 2007; World Bank, 2016). Often such cultural and social norms act as constraints, reinforced by laws that govern family and personal status which shape women career pathways and may in turn further limit their choice and agency. This argument is key to female adult learners at CBE; it is important to understand whether these societal norms and patriarchal practices continue to form a big hindrance to their access and participation.

\subsection{Motivations of Adult Learning}

Adult learning theorists (e.g. Cross, 1981; Knowles, 1989; Jarvis, 1995; Merriam \& Caffarella, 1999; Rogers, 2002) commonly describe adult learners, among other characteristics, as highly diversified group of individuals with widely differing preferences, needs, backgrounds, and skills; they tend to be life-centred in their orientation to learning; they are motivated to learn by a variety of factors; and they maintain active participation in the learning 
process. Taking this into consideration, reasons and purposes why adults learn are varied especially at different stages in an adult learners' life. Understanding these reasons and purposes (motivations for learning) is crucial to all parties involved in the adult learning process.

A well-known model of motivation for adult education is Philippe Carré's (2000) model which is organized on two axes: first axis oriented towards (intrinsic versus extrinsic motivations), while the second axis oriented towards (learning versus participating). The combination of these orientations and axes produces 10 specific motives which are labeled as follows: intrinsic motives include epistemic (learning as a source of satisfaction), socio-affective (to develop social contacts) and hedonic (pleasure taken from space and materials available in the educational setting). Extrinsic motives include economic benefits, prescribed (when the learning activity is provided for by someone else), derivative (participation to avoid unpleasant activities), professional-operational (to develop competencies, knowledge or skills for professional activities), personal-operational (to develop competencies, knowledge or skills required for activities outside the job and working life), vocational (demand for skills or symbolic recognition needed to get, preserve or evolve in a job) and identity-based (appreciation of one's own identity).

Based on her empirical work around the motivational dynamics of a group of Portuguese post-graduates towards their learning, Pires (2009) added a further category to Carré's model of motives which she called existential; motives linked to development of the human being, in the personal sphere.

Boeren (2011) points out that adults do not have one specific motive, but a variety of separate motives. In her study, she explores the profiles and motives of Flemish adult learners in continuing higher education based on a survey among 250 adult learners at Flemish universities and colleges. She concludes that intrinsic motives to participate are highly dominant among Flemish learners in continuing higher education. However, obtaining a certificate is important too, especially among those who have not obtained a degree of higher education before. Motives emerging from external pressure, such as being obliged or forced by others such as employers, are not present among most learners. Likewise, Pires (2009) noted that adult learners reported mainly intrinsic, epistemic motives to enroll and persist in education. Results showed that personal benefits (epistemic motives) like acquiring scientific culture and knowledge were more valued than professional benefits like respond to professional needs or participate in the job organization-or progress in professional career (Pires, 2009).

Different findings come from Carrés (2000) research with adults in short professional courses. Results show that the most prevailing motive for older adult learners was operational-professional, whereas, younger adults expressed superior motives in all areas except operational-professional. Similar findings come from other research which showed that adults are motivated by external factors even though internal motivators are also powerful motivators (Knowles, Holton \& Swanson, 2005). Such internal motives help adults to acquire life-skills, improve job satisfaction, self-esteem, quality of life, and self-actualization opportunities. In the same vein, Kitiashvili and Tasker (2016) examined the relationship between attitudes and motivations of adults to participate in continuing education. A convenience sample that included 300 persons was used. The findings show that adults have positive attitudes towards continuing education, even though their own participation is limited. It was observed that men's motives are mainly linked to extrinsic factors, such as professional orientation, vocational and economic benefits, whereas women and younger adults had mixed motives.

Interestingly, Bye, Pushkar, and Conway (2007)) explored the phenomenological distinction between older and younger students' experience within the intergenerational university classroom by testing levels of motivation to learn, and relationships between age, trait interest, intrinsic motivation, and positive affect in a representative sample of two groups of university undergraduates (18 to 21 years vs. older than 27 years). Findings illustrated that nontraditional undergraduates (above 25) reported higher levels of intrinsic motivation for learning than did traditional ones. Also, intrinsic motivations correlated with positive affect more strongly for nontraditional than for traditional students. Finally, older undergraduates did not differ between levels of intrinsic and extrinsic motivation to learn, indicating that the two goal orientations are equally present for them in the undergraduate academic setting.

The motivations of female adult learners returning to college are various: on one hand, to prepare themselves for future jobs and financial security and to support their families, on the other hand, to pursue their self-actualization after waiting for children to start school or leave home (Hardin, 2008). All in all, previous research shows that, contrary to older male adult learners who are mainly motivated by economic motives, younger adults, and women in particular, have mixed motives (Kitiashvili \& Tasker, 2016); in fact, they declared stronger motives than men (Carré, 2000). The relevance of intrinsic motivations in female adult learning is the key, as Bye, Pushkar, and Conway (2007) stated 'this is particularly outstanding for the nontraditional female students' (Bye et al., 2007, p. 2). Similar results are found in (Rothes, Lemos, \& Goncalves, 2014) in which men scored significantly higher than 
women in the economic, professional-operational, personal-operational, vocational and prescribed motives, that is, in five out of the seven extrinsic motives. Additionally, female adult learners appear to be highly motivated with more perceived competence (self-efficacy) and more self-determined than male learners (Carré, 2000).

\subsection{Barriers of Adult Learning}

The previous review suggests that adults participate in adult education for a variety of reasons and purposes. While some adults may be highly motivated to participate in educational activities, others are confronted with barriers that impede or deter their participation. A well-known approach is Cross's model $(1981,1992)$ that identifies three types of barriers: situational, dispositional and institutional. Situational barriers refer to barriers that arise from one's situation or environment at a point like lack of money and time, having too many personal home, or work responsibilities, childcare, lack of transportation, poor health etc. Dispositional barriers are those relate to the attitude and self-perceptions about one-self as a learner such as negative attitudes and perceptions about further education, its usefulness and the appropriateness of engaging in learning; low self-esteem having poor study habits, and evidence of prior poor academic performance are also dispositional barriers. Institutional barriers are usually caused by institutions of learning including those practices and procedures that exclude or discourage adults from participating in organized learning activities such as inconvenient scheduling; location; lack of interesting, practical or relevant courses; administrative or procedural issues; the lack of information about programmes and procedures, etc. (Cross, 1992). Procedures and time requirements can be problematic too. For example, if potential learners have to complete mounds of paperwork to enroll, they may become discouraged from participating.

While dispositional barriers are directly related to the learners themselves and issues over which they have control, institutional and situational barriers are out of the learner's personal control. However, situational and dispositional barriers can be key to Arab female adult learners. The way in which they make decisions to go back to education is likely to be exceptional and controversial considering their patriarchal traditional culture and societal expected roles. Also, research illustrates that female adult students, compared to men, confront competing pressure of child care, financial, and school responsibilities which would influence their academic experience and progress (Lin, 2016).

Despite the numerous barriers adults face to engage in adult learning activities, many are able to persist and participate. However, when they enter the learning environment, they may be confronted with additional barriers to their learning. The learning environment is a crucial component in the learning situation. Certain features of the physical environment can have negative impact upon adults learning. This can include gloomy rooms that are poorly lit and the traditional seating arrangement where chairs arranged in rows reflecting secondary schooling (Rogers, 2002). Such arrangements are not conducive for adult learners. Also, if an adult had a negative schooling experience, the room arrangement may awaken bad memories (Isaac ,2011).

Instructors too, as part of the institution, play a critical role in addressing/generating barriers. In various cases, they can make the learning environment unfriendly if they show little respect for learners and the knowledge or experience they have. Rogers (2002) suggests that adults have a wealth of experience and instructors should value and capitalize on that experience. This can be accomplished simply by including and building upon the student's experiences in the learning process.

\section{Methodology}

To answer questions mentioned earlier, this study follows a mixed approach utilizing both quantitative and qualitative methodologies. Data was collected from a randomly selected sample from the adult female learners' population at CBE which is 1693 female students. Questionnaire and focus groups were used to elicit rich qualitative data as well as quantitative representative data.

The questionnaire used in this research was constructed upon the main categories of the research: motivations and needs of adult female learners, and, difficulties and barriers of their learning experiences. These categories are then interpreted into a total of 30 statements to obtain learners' responses of agreement and disagreement on a five-point Likert scale. Data on a number of demographic and background variables are also collected. Issues of validity are considered before distributing. Face validity of the questionnaire is examined by a number of experts. Content validity is also checked by measuring internal consistency coefficients of the main constructs which proved to have very good scores as shown in Table 1. Reliability of the scale is also determined through Cronbach alphas which reported good scores for the main constructs of the scale as shown in Table 2.

Between February and April 2018, 220 questionnaires were distributed to potential learners; the response rate was about $80 \%$ and 176 were completed and returned. The quantitative data was analyzed using the statistical package 
for social sciences (SPSS) WIN version 20.0. Statistical analyses include descriptive statistics (frequencies, percentage, mean, and standard deviation) as well as inferential statistics like (Scheffe test and ANOVA).

Regarding the qualitative data, four focus groups were conducted in May 2018 with 38 female adult learners. The interviews which lasted about 30-45 minutes were taped after obtaining consents from participants. Being a female researcher facilitated this task; for a woman to be understood in any social research, it may be necessary for her to be interviewed by another woman (Cook \& Fonow, 1986). The qualitative data were transcribed then analyzed by following categorizing techniques such as coding, content and thematic analysis. Based on the theoretical framework adopted, Carré's model of motivations and Cross's three types of learning barriers, as well as emerging themes, codes were categorized into major themes, each of which contained subthemes.

Table 1. Internal consistency coefficients of the scale

\begin{tabular}{ccc}
\hline Tools & Items & Internal consistency coefficients \\
\hline \multirow{2}{*}{ Motives } & Internal & 0.834 \\
& External & 0.923 \\
& Internal & 0.833 \\
Difficulties & Institutional & 0.793 \\
& Positional & 0.861 \\
\hline
\end{tabular}

Table 2. Cronbach's Alpha coefficients for the scale

\begin{tabular}{ccc}
\hline Tools & Items & Cronbach's Alpha coefficients \\
\hline \multirow{4}{*}{ Motives } & Internal & 0.608 \\
& External & 0.712 \\
& Total & 0.784 \\
& dispositional & 0.750 \\
Difficulties & Institutional & 0.534 \\
& Situational & 0.592 \\
& Total & 0.804 \\
\hline
\end{tabular}

\section{Profile of the Sample}

The first research question aimed to identify the profile of adult female learners who participate in CBE in terms of their socio-demographic, professional and academic background. Statistics show that higher educated female students (with two years diploma) participate in CBE more than less educated ones (with high school only). They also achieve very good academic scores; around $67.6 \%$ of the sample had a GPA of 3.00 and more. This is an indicator that there is a relationship between adults' educational attainment and their participation in education. Similar result has been confirmed in previous research (Field, 2000; Nesbit, 2006; Boeren, 2011). Moreover, Illeris (2003) which pointed out those higher educated adult learners have better attitude towards learning and more confidence in completing the course successfully. Regarding the age of the sample, $72.7 \%$ of them are in the stage of early or mid-adulthood (between 23-35). It is apparent that participation at CBE decreases with age; the breaking point at which participation decreases is the age of 35 . However, participation of older female learners is still visible (the eldest of the respondents was 49).

Statistics show that questionnaire respondents come from the six governorates of Kuwait, much from governorates which retain their nomadic and tribal traditions like (Jahra-Ahmadi-Farwanyia). Regarding females' family situation, $69.9 \%$ of them are married, and $74.5 \%$ have children (half of them have at least three children).

\section{Data Analysis}

In the following sections both quantitative and qualitative data is integrated and presented under the headings of the main study themes: motives for enrolling in CBE and barriers of adults' learning.

\subsection{Motives for Enrolling in CBE}

In the first section of the questionnaire respondents were asked to indicate their motivational orientations towards 15 purposes for their participation in HE, six purposes represent intrinsic motivations and nine represent extrinsic motivations. Results show that respondents are strongly driven by both intrinsic $(m=4.45)$ and extrinsic motives $(m=4.49)$ to enrol CBE, although extrinsic motivations appear to be more important. Findings indicate that the most important motives for these learners are as follow: to obtain a higher qualification, seeking self-actualization, 
and to get better job opportunities, whereas the least important motivator is the flexibility of the admission policies. Table 3 provides the mean, standard deviation, and rank for each motive (item).

Equally, most interviewees participated in focus groups expressed mixed motives to enrol in CBE. Reasons like 'to improve my qualifications, 'to enhance my career prospects', and 'to enhance my financial situation' appear to be the primary motivating factors. Meanwhile, responses as 'to prove myself', 'to achieve my old dream to be a teacher', and 'to fulfil my desire to learn' are also endorsed in the interviews. Overall, in accordance with results from previous research, motivations of female adult learners are seen as either employment related or to do with proving themselves, with slightly higher work-related motives. Such finding is expected given that most of the sample are employed and enrolled CBE through scholarships (study leave) from their employers, meaning that they are still active in the labour market and they wish to improve their employment status with considerable support from their employers, mainly the government. To some extent, this is a positive indication of policy efforts towards women economic empowerment in the country.

In line with the statistical data, the flexibility of admission rules (the least mean $=3.851$ ) does not act as key motivator. In fact, respondents perceive these rules as demotivators delaying their participation in HE. Illustrative of these sentiments are the following:

\section{'I had to redo high school many times to get the required GPA';}

'to get a study leave in my department is so competitive... the list is very long and I had to wait 6 years to be accepted in $C B E$ ';

'the civil authority conditions are so tough...I tried my best to meet them but I couldn't...finally I decided to have a fresh start... to quit my job, to forget about my diploma and redo high school again'.

The most notable remark pertains to the lack of practices of widening participation. Almost all of the participants complained that their previous qualifications, life and work experiences are not recognised as an alternative form of access credentials. Such issues form central challenges for interested adults. In previous research, such facilities were seen as key components in increasing learning opportunities for adult learners who lack traditional academic qualifications or who have been out of the education system for a long time (Alshebou, 2010).

Based on analyses of variance (ANOVAs), differences in respondents' responses of motivations according to their demographic profile are examined. Statistical findings did not reveal any significant differences according to students' demographic variables except for their age. To assess the age variable, respondents were divided into three age groups: below 30, 30-35, and above 35. Results indicate significant differences in intrinsic motivations at $\mathrm{p}<0.05$ according to learners' age group. Using Scheffe test, findings show that older adults $(\mathrm{m}=27.458)$ are the ones who are mostly intrinsically motivated to participate in learning at CBE followed by the youngest age group $(\mathrm{m}=26.686)$, while the middle age group appear to be the least group motivated by intrinsic motives $(\mathrm{m}=26.169)$. Correspondingly, previous research illustrates that intrinsic motives increase among older students; thus, they are more likely to seek self-actualization instead of career development, especially when compared with younger students in the same settings (Bye et al., 2007; Lin \& Wang, 2016; Rothes et al., 2014). This can be justified that older adult students are more financially secure compared with younger adult students. 
Table 3. Means, Std. deviation, and ranks of motives

\begin{tabular}{|c|c|c|c|c|}
\hline No. & Item & Mean & Std. Deviation & Rank \\
\hline a5 & To continue education and get higher qualification & 4.8523 & .46696 & 1 \\
\hline a9 & to seek self-actualization & 4.8011 & .53474 & 2 \\
\hline a1 & To get better job opportunity & 4.7314 & .57922 & 3 \\
\hline a10 & To be an active citizen & 4.6989 & .50732 & 4 \\
\hline a6 & To widen promotion opportunities & 4.6897 & .67679 & 5 \\
\hline a4 & To improve financial situation & 4.6609 & .67573 & 6 \\
\hline a3 & To improve skills and capabilities & 4.6477 & .53537 & 7 \\
\hline a15 & passion to learn & 4.6457 & .57752 & 8 \\
\hline a12 & encouragement from others & 4.4571 & .86910 & 9 \\
\hline a11 & To better perform family responsibilities & 4.4034 & .79411 & 10 \\
\hline a2 & interest in the subject & 4.3086 & .80707 & 11 \\
\hline a14 & To feel better & 4.1534 & 1.04433 & 12 \\
\hline a7 & To invest my spare time & 4.1307 & .87503 & 13 \\
\hline a13 & To make new relationships & 4.0457 & .98738 & 14 \\
\hline a8 & Flexibility of admission rules & 3.8514 & 1.04534 & 15 \\
\hline
\end{tabular}

\subsection{Barriers of Adults Learning}

In the second section of the questionnaire respondents were asked to indicate their responses towards 15 types of potential barriers they face in their learning experience, four dispositional, six institutional, and five situational. Statistics illustrate that responses towards learning barriers come in moderate and less than moderate degrees. The most significant barriers expressed by respondents are the institutional ones $(m=3.23)$ followed by the dispositional barriers $(\mathrm{m}=2.55)$, then the situational barriers $(\mathrm{m}=2.44)$. Breaking down the scores of these different barriers, mean scores show that the primary five barriers for learners are totally institutional. The first three barriers include 'my experience is not appreciated by teachers', 'teachers do not give enough opportunity to share my experience with other students', and 'rules are strict and do not view us as non-traditional students'. On the other hand, barriers like 'I've chosen my study major upon family wish' and 'I do not get enough support from my family' have yielded the least scores of agreements, meaning that respondents do not see them as important difficulties in their learning experience. Table 4 presents the mean, standard deviation, and rank for each barrier (item).

Table 4. Means, Std. deviation, and ranks of barriers

\begin{tabular}{llccc}
\hline No. & Item & Mean & Std. Deviation & Rank \\
\hline b7 & my experience is not appreciated by teachers & 3.4943 & 1.12125 & 1 \\
b4 & teachers do not give enough opportunity to share my experience with other students & 3.4138 & 1.12822 & 2 \\
b15 & rules are strict and do not view us as non-traditional students & 3.3182 & 1.37359 & 3 \\
b12 & Study requirements are different from what I used to & 3.2807 & 1.21879 & 4 \\
b5 & College services do not meet my needs & 3.2299 & 1.29205 & 5 \\
b3 & I face difficulty in working with young students & 3.1214 & 1.28147 & 6 \\
b11 & Family responsibilities hinder my studies & 3.0460 & 2.53944 & 7 \\
b2 & Teachers' teaching methods do not suit my age and experience & 2.7257 & 1.84894 & 8 \\
b6 & I find it difficult to make social relationships with young students & 2.6034 & 1.28944 & 9 \\
b9 & My financial obligations obstruct my academic progress & 2.5625 & 1.30343 & 10 \\
b10 & My health status hinders my studies & 2.5202 & 1.17923 & 11 \\
b8 & I feel embarrassed to interact in the classroom & 2.3864 & 1.29995 & 12 \\
b13 & I do not possess the right studying skills & 2.1453 & 1.16319 & 13 \\
b1 & I've chosen my study major upon family wish & 2.0857 & 1.20753 & 14 \\
b14 & I do not get enough support from my family & 2.0402 & 1.17468 & 15 \\
\hline
\end{tabular}

The qualitative data collected also supports these results. Almost all interviewees agreed that institutional issues represent the dominant challenges in their experience. However, when it comes to adults' experience and teachers' appreciation, the picture seems to be inconsistent. Different views are expressed. Some learners think that their 
views, experiences, and knowledge are regarded and appreciated by teachers; one interviewee explained that:

'some teachers are considerate and supportive...they note our knowledge and give some space'

'some teachers consider that we are not young and talk to us in a slightly different way'

In contrast, many interviewees feel undervalued and complain that:

'a number of teachers had advised us to go back home and look after our families and kids... they see us incapable of the study requirements'

This discouraging attitude from teachers can have negative impact upon adults learning. In this sense, Raffini (1993) claims that the beliefs instructors have about teaching and learning and the nature of the expectations they hold for learners exert a powerful influence on adults' learning. This can be justified that most teachers in CBE are pedagogically qualified to teach traditional young students and not adult learners.

Nonetheless, data shows that most of the sample believes in themselves and in their competences. One interviewee state that:

'our problem is with the teachers not classmates...because we ask and discuss, we are a headache for them'

Once more, it appears that opportunities for female adult learners to interact, to draw on their personal experiences and even to engage actively in the learning experience are limited. In the adult education tradition, instructors must not minimize the learners' experiences in any way; 'when this experience is devaluated or ignored (e.g. by the teacher), this implies a rejection of the person, not just the experience' (Rogers, 2002, p. 73). That being said, it is justified that being in a traditional college, teachers need to follow a more pedagogic, teacher-focused approach to help attain instructional objectives. This is a case very common in classes where most of the student body are young learners, and teachers lack the proper andragogical knowledge or the desire to engage in this kind of teaching.

On the other hand, the aforementioned comment illustrates respondents' acknowledgment of the small gap between them and young learners. This can be justified that most learners are in the stage of early or mid-adulthood (between 23-35) as statistically explained earlier, meaning that a considerable number of adults decide to return to education at a rather young age. More importantly, most interviewees expressed their satisfaction towards these classes.

Administrative and procedural issues like inconvenient scheduling, complicated paperwork, bureaucratic procedures, unfriendliness staff, and poor facilities are also seen as major obstacles. This can be identified from comments like:

'unlike young students, we need to update our records at the civil authority every semester... it is a long registration procedure'

'incomplete schedules make things difficult for us, especially that we have a time limit to graduate.......otherwise, they cease our study leave'

'services in the college are really bad... small library, crowded noisy lounges ...no nursery for kids... sometimes we skip classes to stay with kids at home'

Previous research showed that lack of time and funding constraints are the main obstacles in adult learning. Pires (2009) commented that this is a general rule regardless of contexts, systems and cultures. In contrast, this is not the case in this study. This can be explained that studying at $\mathrm{CBE}$ is free and that most female adult learners are enjoying paid leaves or are receiving study allowance from the government.

Interestingly, qualitative data signaled a number of important situational issues. Interviewees expressed that they do not experience lack of family support. In fact, most of them enjoy full support and help from their families, especially and surprisingly, from their husbands who had formerly rejected the idea of going back to education. Some of the comments made are:

'now because life circumstances have changed...family income is not enough, he likes the idea and actually he is doing most of the official paperwork for me, although ten years ago, he was completely against this...'

'my husband helps me a lot, especially, at exams time, he takes the children out to give me more time studying'

'he used to reject the idea of college and driving...now he persuaded me to get a driving license so I can drive to the college'

Family interference in choosing what to study was not also perceived as a significant barrier. At one point, 
interviewees claimed that they have the choice to select study major that interests them. However, for those on study leave, this choice is relatively limited to options offered by their employers, normally government departments, which specify certain majors linked to their occupation. According to theory, it tends to represent an institutional rather than a situational barrier, particularly that changing study major is considerably forbidden for those learners. This can be found in repetitive comments like:

'my family has nothing to do with my major...my employer assigned only three options to choose...nothing else'

'I did not like the majors specified by my department... therefore I had to quit my job and redo high school and chose the study major I like'

Above all, family commitment still represents a top priority over females' great educational aspirations. In this context, Gallant (2010) commented that females in GCC societies 'can't voluntarily admit to not wanting to become a wife or mother' A number of interviewees state that:

'late classes are not for us ...I have kids...'

'I need to go home early to help my kids studying'

As regards differences in respondents' responses, One-Way Anova tests are done to assess any differences towards learning barriers according to their demographic variables. Findings show that there are significant differences in this construct according to learners' GPA and their place of residence only as shown in Table 5. Regarding the GPA variable, respondents were divided into three groups: 3.00 points and less, 3.00-3.50 points, and 3.50 and above. Results indicate significant differences in situational barriers at $\mathrm{p}<0.05$ according to learners' GPA. Using Scheffe test, it appears that students with 3.00 point and less are the ones who perceive these barriers most $(\mathrm{m}=14.482)$, followed by students with the highest GPA $(\mathrm{m}=11.769)$, then the students with the median GPA $(\mathrm{m}=11.487)$. Clearly, competing pressures in juggling the role of student and family member can have negative impact upon learners' academic performance (Lin, 2016). This is understandable since most of the samples are married with children; thus, they occupy a great number of characters such as mothers, wives, employees, and community members.

Also, to assess differences concerning the residence variable, results illustrate that there are significant differences in responses towards the construct in general as well as dispositional barriers according to learners' place of residence. Using Scheffe test, statistics indicate that those who live in Jahra $(\mathrm{m}=12.600)$ are the ones who perceive these barriers most, whereas those who live in Mubarak Alkabeer perceive them least $(\mathrm{m}=8.576)$. Generally, the entire population in Kuwait is urban. Nevertheless, Kuwaitis often refer to "inner" Kuwait (areas like Aseema, Hawally, Mubarak Alkabeer) with its more liberal and modern atmosphere and "outer" Kuwait, farther from the central city like Jahra, where conservative Bedouin and tribal traditions and norms are much stronger. Unsurprisingly, females from these areas experience various barriers due to their traditional lifestyles, societal obligations, and men's hegemony which can lead to some dispositional difficulties such as negative self-perception, low self-efficacy and poor social and academic skills.

Table 5. Differences in barriers according to respondents' GPA and residence

\begin{tabular}{lllcccc}
\hline Variables & Items & Df & Mean Squ. & F & Sig \\
\hline \multirow{4}{*}{ GPA } & Dispositional barriers & 2 & 17.781 & 1.219 & 0.299 \\
& Institutional barriers & 2 & 52.394 & 2.460 & 0.090 \\
& Situational barriers & 2 & 89.908 & 3.623 & $0.030^{*}$ \\
& Total & 2 & 94.679 & 0.709 & 0.495 \\
& Dispositional barriers & 5 & 53.877 & 4.078 & $0.002^{* *}$ \\
& Residence & Institutional barriers & 5 & 24.406 & 1.238 & 0.294 \\
& Situational barriers & 5 & 34.661 & 1.481 & 0.199 \\
& Total & 5 & 275.934 & 2.355 & $0.043^{*}$ \\
\hline
\end{tabular}

$* \mathrm{p}<0.05 ; * \mathrm{p}<0.01$

\section{Concluding Remarks}

The results of this study contribute to our understanding of the learning experiences of female adult learners at $\mathrm{CBE}$ in terms of their motives and obstacles they face. An analysis of the combined quantitative and qualitative data suggests several concluding remarks. First, in Kuwait, there appears to be a discrepancy between ambitions 
expressed in national policies and institutional practices. This study reveals that governments' initiatives towards a mass HE in general and adult education in particular are still under expectations. Since 2003, high-level recommendations presented in the national paper 'Education for All' (Ministry of Education, 2003) like establishing a national strategy for adult education and providing more technical and applied learning opportunities for adult learners have not yet yielded any significant response across governmental entities. Legislations for adults to continue education are not clear to concerned parties at a national level; they are read and interpreted differently by HE institutions, employers and governmental bodies. The most recent law declared by the Civil Service Authority to stop study leaves for those above the age of 40 (Alhadad, 2018) can also be seen as disappointing. Thus, developing a strong mediation system is crucial for linking interested persons with educational institutions as well as employers through information and consultations.

Apparently, the Kuwaiti government stands at a crossroads. The government vision to transform the State into a leading regional financial, commercial, and cultural hub by 2035 requires a knowledge-driven labour market that supports everybody to participate in education, whether continuing education or HE. At one hand, the government is fully aware of the rewards of investment in adults' education, and perceives it as a good economic practice as expressed in national strategies and reports. Yet, since HE is free to nationals, it can be argued that the government might be reluctant to undertake the substantial efforts to broaden access, remove existing barriers, develop new paths and structures to qualifications, and allocate more resources and new HE infrastructures; a further burden on government expenditure.

The second remark pertains to the sample's major studies; more than $57 \%$ of the questionnaire respondents are enrolled in humanities and arts. It must be said that the same situation can be found in younger female population where female students enroll in social sciences majors more than exact science ones. Unlike traditional students, opportunities for female adult learners to enroll science disciplines are limited, and attempts to change study major are strictly declined by the Civil Services Authority. This reveals an imbalance in the educational choices available for adult learners. For the majority of the sample, the second-chance policy of obtaining a degree which one had failed to obtain in the past is their gateway to a better career. At the moment, the labour market in Kuwait is in need of females with more science and technical qualifications (World Bank, 2016) and highly skilled female employees are a boost to the country's economy and could increase innovation and competitiveness (UNDP, 2012). It is a task of the government to plan the shaping of an educational offer in order to diminish these gaps and labour shortages.

Another disparity is the traditional organization of HE institutes. The data shown above highlights several concerns regarding the organization of CBE for nontraditional students. Data analysis shows that female adult learners in Kuwait face rigid admission criteria as well as long complicated paperwork to enroll CBE. Although CBE foresees specific tracks for adult students, the number of enrolments per year is often rather low and just counts a very limited number of students. This practice can hinder many female adult candidates from participation. Moreover, the traditional course format of CBE is no longer attractive to many adult learners as they have distinctive employment or societal position. Many adults no longer want to take years to obtain a degree or certificate. Adults want to get their credentials as quickly as possible. On similar grounds, Chao, DeRocco and Flynn maintain that 'traditional structure and organization of higher education pose significant barriers to adult learners' (Chao et al., 2007, p. 3). Redefining the current traditional organization of HE is highly needed. A very beneficial approach might be adopting a dynamic, coherent, integrated scheme to adult learning policies and strategies within the whole HE system. Adult learners want to minimize the amount of time spent on continuing education and maximize their results, thus it is strongly recommended that flexibility is built into the programmes, giving them a choice of duration and implementation. It is more convenient for adults when institutions offer multiple entries, exit, and re-entry points for learners, with flexible modes like weekend classes and online courses. Developing an effective validation system for non-formal education or experience-equivalency is also crucial.

In this study, empirical evidence displays a number of andragogical concerns. Current CBE classes may not always address adults' interests, as the ultimate goal in any traditional university is to prepare students for graduation. However, care should be taken that excessive structure and authority in the programme do not become a de-motivation for learning. Various indicators reinforce that female adult participation will be put in jeopardy if present practices continue on its current trajectory. Poor learning environment, inconvenient facilities, unsupported teachers, traditional teaching methods, inflexible course structures and unfriendly staff are likely to impede female adults' learning. Therefore, CBE should consider providing several services for female adult learners such as long library working hours, separate registration and orientation, separate lounges, and day-care centers. To be more specific, student affairs departments can support offering tutoring assistance to refreshing adults' study skills, as well as counseling and family-related sessions. Regardless of the context, instructors must also do their part to 
eliminate barriers to learning. Occasionally some female adult learners lack a motivation to learn, and, instructors do not employ any techniques to motivate these females to learn. Innovative teaching methods like group discussion tend to be very effective with adults as it partially meets their need for communication and social interaction. In addition, instructors could invite and encourage female adult students to share their life experiences towards a special topic. In this way, not only female adult learners could build a good rapport and get involved with the class, younger students also have an opportunity to gain practical knowledge from real life examples. To achieve this, instructors at CBE in particular, and in HE in general, should be offered continuing professional development courses around the unique characteristics of adult learners. These courses can be mandatory or optional; a good example is the Postgraduate Certificate/Certificate in Education (PGCE/Cert Ed) for the Further Education Learning and Skills Sector offered in the UK.

Another noteworthy remark is the theme of feminism which emerges to have a specific connotation in this study, echoed to the 'Arab feminism' suggested by Gallant (2010), and Kawanzaruwa (2015). This female group reports early marriage as the major reason for not completing their degrees. In few cases, the impact of societal norms and masculine authority was big as male guardians, mainly husbands, acted as decision makers and female learners appeared to be compliant. However, many of the interviewees assert that it was their own decision not to continue their studies and to stay at home prioritizing their families over their careers. Apparently, it is still considered normal for women to consult their spouse or parent to work or to go back to education; in fact, it is within this patriarchal system those females enjoy security. Opposite to the old stereotype of GCC women as powerless victims of repressive patriarchal families, this study demonstrates that most female adult learners are active agents in their society, working hard for their attainments, making their own decisions, enjoying support from families, and many of them paly a good role model for their husbands to go back into education. At the same time, they are committed to their social values which might sometimes limit their choice and agency. They acknowledge that they are not in a gender struggle and they perceive these traditions need not be fixed or changed. This is the kind of feminism, emancipation, and empowerment they look for. At some point, it is fair to say that masculine hegemony in Kuwait continues to represent a hindrance to female adults' access and participation in HE; albeit in a lesser extent than before. In the last decades, a social change is gradually happening due to several factors like government policies to increase women's participation in education and workforce, cultural openness, the increasing number of educated men, as well as the high living expenses which demands extra income making; the average monthly expenditure of Kuwaiti families was estimated to be around 10,000 \$ in 2013 (Central Statistical Bureau, 2013, p. 2). This figure will have only risen in the last six years.

Last of all, the motives instrument used in this study can benefit pedagogical practice in different adult learning contexts in many ways. Instructors could offer this questionnaire at the onset of their programmes to their adult learners. This will assist in getting a more precise, more conceptually sound vision of their learners' groups, and thus course preparation time, trainer anxiety and new materials development needs are likely to be reduced with such an approach. Similarly, adult learners can use this instrument in self-diagnosis procedures to help them reflect on their dispositions and aspirations.

\section{Future Research}

Based on the findings of this study and considering the relatively scarce research in the field of adult learning in Kuwaiti HE:

1) Similar study is required with male adult students at $\mathrm{CBE}$ and other HE institutions to verify and compare findings.

2) Future research should further investigate both female and male adult learners' motivational orientations and how they relate to their retention, completion and achievement.

\section{Acknowledgments}

This research was supported and funded by The Public Authority for Applied Education and Training, Kuwait, Research project (BE-17-12).

\section{References}

Alansari, E. (2002). The Aims, Obstacles, and Aspirations of Learners in Adult Education Centers in the State of Kuwait. The Educational Journal, 16(62), 15-52.

Alhadad, H. (2018, September 3rd). A message to the President of Civil Service Authority. Alanba Newspaper (p. $15)$.

Alshebou, S. (2007). A Comparative Study of University Continuing Education Policy and Practice. Case 
Studies from Kuwait and England (Unpublished Doctoral Thesis). University of Nottingham, UK.

Alshebou, S. (2010). The benefits of adult learning: Continuing education and the development process in the state of Kuwait. The College Student Journal, 44(4), 860-877.

Alwogayan, F. (2010). The Sociocultural and constitutional dilemmas for empowerment and citizenship: The case of Kuwaiti woman. Kuwait: Strategic and future studies center, Kuwait University.

Attyiah, A. (2010). Woman and Development in GCC Countries symposium. Riyadh: The Secretariat General of GCC.

Boeren, E. (2011). Profiles and motives of adults in Flemish continuing higher education. European Journal of Higher Education, 1(2-3), 179-191. https://doi.org/10.1080/21568235.2011.629488

Bye, D., Pushkar, D., \& Conway, M. (2007). Motivation, interest, and positive affect in traditional and nontraditional undergraduate students. Adult Education Quarterly, 57(2), 141-158. https://doi.org/10.1177/0741713606294235

Carré, P. (2000). Motivation in Adult Education: From Engagement to Performance. Paper presented at (AERC) Adult Education Research Conference 2000, in Vancouver, Canada, June 2000. Retrieved from http://www.edst.educ.ubc.ca/aerc/2000/Carrép1-final.PDF

CBE. (2018). Anuual statistical report. Kuwait: Vice Dean Office.

Central Statistical Bureau. (2013). Household income and expenditure survey (January-December 2013). Kuwait.

Chao, E. L., DeRocco, E. S., \& Flynn, M. K. (2007). Adult learners in higher education: Barriers to success and strategies to improve results. Washington, DC: U.S. Department of Labor.

Cook, J., \& Fonow, M. (1986). Knowledge and women's interests: issues of epistemology and methodology in $\begin{array}{lllll}\text { Feminist Sociological } & \text { Research. } & \text { Sociological }\end{array}$ https://doi.org/10.1111/j.1475-682X.1986.tb00073.x

Cross P. (1981). Adults as learners. San Francisco: Jossey-Bass.

Cross, P. (1992). Adults as learners: Increasing participation and facilitating learning. San Francisco: Jossey-Bass.

Field, J. (2000). Lifelong learning and the new educational order. Stoke on Trent, UK: Trentham Books.

Gallant, M. (2010). Broken Silence: a commentary on women's entrepreneurship in the United Arab Emirates. The International Journal of Entrepreneurship and Innovation, 13(2), 81-92. https://doi.org/10.5367/ijei.2012.0071

Hafez, F. (2008). Woman's Empowerment in the Gulf: inside and outside debate. Abu Dhabi: The Emirates Centre for Strategic studies and research.

Hardin, C. J. (2008). Adult students in higher education: A portrait of transitions. New directions for higher education, 144, 49-57. https://doi.org/10.1002/he.325

Houle, C. O. (1961). The inquiring mind. Madison, WI: University of Wisconsin Press. Republished 1988.

Illeris, K. (2003). Towards a contemporary and comprehensive theory of learning. International Journal of Lifelong Education, 22, 396-406. https://doi.org/10.1080/02601370304837

Isaac-Savage, P. (2011). Barriers to adult education participation, distance education, and learning. In Encyclopedia of information communication technologies and adult education integration (pp. 1100-1112) V. C. X. Wang: Information Age Publishing Editors. https://doi.org/10.4018/978-1-61692-906-0.ch067

Jarvis, P. (1995). Adult and Continuing Education. Theory and Practice. London: Routledge

Kawanzaruwa, G. (2015). Lived experiences of emirati senior women managers in higher education: a narrative analysis (Doctoral Thesis, Durham University). Research from http://etheses.dur.ac.uk/10993/

Kikoski, C. K. (2008). Feminism in the Middle East. Reflections on Ethnographic Research in Lebanon. Journal of Feminist Family Therapy, 11(4), 2000. https://doi.org/10.1300/j086v11n04_10

Kitiashvili, A., \& Tasker, P. (2016). The relationship between attitudes, motives and participation of adults in continuing education: The case of Georgia. International Journal of Research and Reviews in Education, 3, $13-21$. 
Knowles, M. (1989). The making of an adult educator. San Francisco: Jossey-Bass

Knowles, M., Holton, E., \& Swanson, E. (2005). The adult learner: The definitive classic in adult education and human resource development (6th ed.). Amsterdam: Elsevier. https://doi.org/10.4324/9780080481913

Lin, X. (2016). Barriers and challenges of female adult students enrolled in higher education: A literature review. Higher education studies, 6(2), 119-126. https://doi.org/10.5539/hes.v6n2p119

Lin, X., \& Wang, C. (2016). Exploring Predictive Factors Influencing Returning International and American Adult Learners' Motivational Orientations. International Research in Higher Education, 1(1), 1-8. https://doi.org/10.5430/irhe.v1n1p1

Mazawi, A. E. (2007). Beseiging the King's Tower? Engendering academic opportunities in the Gulf Arab states. In C. Brock, \& L. Z. Levers (Eds.), Aspects of Education in the Middle East and North Africa (pp. 77-98). Oxford Studies in Comparative Education. Oxford: Symposium Books

Merriam, S., \& Caffarella, R. (1999). Learning in adulthood. A comprehensive guide. San Francisco: Jossey-Bass.

Ministry of Education. (2003). Report on Education for All in The State of Kuwait. Kuwait: Ministry of Education.

Nesbit, T. (2006). What's the matter with social class? Adult Education Quarterly, 56(3), 171-187. https://doi.org/10.1177/0741713605286173

Pires, A. (2009). Higher education and adult motivation towards lifelong learning: an empirical analysis of university post-graduates' perspectives. European journal of vocational training, No. 46-2009/1.

Raffini, J. (1993). Winners without losers: Structures and strategies for increasing student motivation to learn. Boston: Allyn and Bacon. https://doi.org/10.1177/019263659407856019

Rogers, A. (2002). Teaching Adults (3rd ed.). Open University Press: UK.

Rothes, A., Lemos, M., \& Gonçalves, T. (2014). Motives and beliefs of learners enrolled in adult education. Procedia-Social and Behavioral Sciences, 112, 939-948. https://doi.org/10.1016/j.sbspro.2014.01.1252

Singh, M., Idris, H., \& Chehab, M. (2018). Pathways to Empowerment: recognizing the competences Syrian refugees in Egypt, Iraq, Jordan, Lebanon and Turkey. Hamburg: UNESCO Institute for lifelong learning.

Supreme Council for Planning and Development. (2007). Kuwait Vision 2010-2035. Kuwait: General secretariat of the supreme council for planning and development.

UNDP. (2012). Economic empowerment of Kuwaiti women. Kuwait.

Walters, M. (2005). Feminism: A very short introduction. UK: Oxford University Press.

World Bank. (2016). Paving the way for women's economic inclusion in the Gulf Cooperation Council. GCC Engagement Note: 3. https://doi.org/10.1596/24419

\section{Note}

Note 1. CBE follows single-gender education and combines two different colleges for female and male students.

\section{Copyrights}

Copyright for this article is retained by the author(s), with first publication rights granted to the journal.

This is an open-access article distributed under the terms and conditions of the Creative Commons Attribution license (http://creativecommons.org/licenses/by/4.0/). 